\title{
44564 - CHARACTERISTICS OF STORED RAT BLOOD: CAN IT DELIVER OXYGEN TO THE BRAIN?
}

\author{
Andrea Rigamonti, Department of Anesthesia, St. Michael's Hospital, Toronto, ON, \\ Canada; \\ Katherine Nix, Department of Anesthesia, University of Toronto; \\ Anya McLaren, Department of Anesthesia, University of Toronto; \\ T Ragoonanan, Department of Anesthesia, University of Toronto; \\ CD Mazer, Department of Anesthesia, University of Toronto; \\ J Freedman, Department of Medicine, University of Toronto; \\ GMT Hare, Department of Anesthesia, University of Toronto;
}

INTRODUCTION: Stored blood undergoes changes in red cell morphology (1) and increased oxygen affinity which may impair its ability to deliver oxygen to tissue. However, the effect of blood storage on tissue oxygen delivery has not been clearly established $(2,3)$. We assessed the effect of 7-day storage of autologous blood on red cell characteristics and cerebral oxygen delivery following hemorrhage and resuscitation in anesthetized rats.

METHODS: Stored whole rat blood (7 days in CPDA-1 at 4oC) approximates 30 day stored autologous human blood. With Animal Care Committee approval, isoflurane anesthetized rats underwent tail artery and vein cannulation to measure mean arterial blood pressure (MAP), arterial blood gases (ABG) and hemoglobin concentration by co-oximetry (Radiometer) and to perform $30 \%$ hemorrhage and resuscitation. A combined oxygen sensitive microelectrode and laser Doppler flow probe (Oxford Optronix) was placed in the hippocampus to measure cerebral tissue oxygen tension (PBrO2) and regional cerebral blood flow (rCBF). After establishing a baseline, $30 \%$ hemorrhage was performed by removing $15 \mathrm{ml} . \mathrm{kg}-1$ of blood over 10 minutes. After an additional 20 minutes, an equal volume of fresh autologous or 7 -day stored blood ( $\mathrm{n}=6$ per group) was re-infused over 10 minutes. Data was recorded for an additional 60 minutes. rCBF measurements were normalized to the baseline. Data (mean \pm SD) was analyzed by ANOVA.

RESULTS: After 7 days, there was a significant reduction in $\mathrm{pH}(6.79 \pm 0.03)$ and $\mathrm{PaO} 2(62 \pm$ $8.2 \mathrm{mmHg}$ ), an increase in $\mathrm{PaCO} 2(95.6 \pm 13.4 \mathrm{mmHg})$, and no detectable plasma hemoglobin in stored rat blood. Red cell morphology changed from $95 \pm 4 \%$ discocytes in fresh blood to $39 \pm$ $11 \%$ discocytes, $25 \pm 12 \%$ ovalocytes, $31 \pm 19 \%$ echinocytes and $7 \pm 4 \%$ spheroechinocytes in stored blood. Following hemorrhage, there was a comparable drop in MAP and $\mathrm{PBrO} 2$ in both groups while $\mathrm{rCBF}$ remained stable. Resuscitation with stored blood returned MAP (92 \pm 16 $\mathrm{mmHg})$ and $\mathrm{PBrO} 2(24 \pm 5 \mathrm{mmHg})$ to baseline values, while $\mathrm{rCBF}$ remained stable $(1.2 \pm 0.1)$. Resuscitation with fresh blood returned MAP to baseline (105 $\pm 16 \mathrm{mmHg})$ while both $\mathrm{PBrO} 2$ $(42 \pm 11 \mathrm{mmHg})$ and $\mathrm{rCBF}(1.9 \pm 0.4 \mathrm{mmHg})$ increased significantly relative to baseline and stored blood values ( $\mathrm{P}<0.05$ for all). Co-oximetry and $\mathrm{ABG}$ data did not differ between groups. DISCUSSION: These data demonstrate that storage of rat blood resulted in a characteristic blood storage lesion. Resuscitation with stored blood restored MAP and PBrO2 to baseline 
values demonstrating its ability to improve hemodynamic stability and tissue oxygen delivery. However, resuscitation with fresh blood produced a greater increase in both $\mathrm{PBrO} 2$ and $\mathrm{rCBF}$, relative to that observed after resuscitation with stored blood. These data demonstrate that stored blood has an impaired ability to deliver oxygen to the brain in rats.

REFERENCES: (1) J Surg Res 2002; 102:6; (2) Transfusion 2004;44:1626 (3) Anesth Analg 2005;100:912. 